\title{
From insect eye to vertebrate muscle: redeployment of a regulatory network
}

\author{
Frédéric Relaix and Margaret Buckingham ${ }^{1}$ \\ Centre National de la Recherche Scientifique, Unité de Recherche Associé 1947, Département de Biologie Moléculaire, \\ Institut Pasteur, 75724 Paris cedex 15, France
}

\begin{abstract}
The redeployment of the same signaling systems at different places and times during embryogenesis, and the conservation of these systems across species, from invertebrates to vertebrates, has emerged as a major theme of biology. This conservation also applies to transcriptional regulation; the Hox genes are a classic example. More recently a striking illustration of the phenomenon was provided by the demonstration that homologous regulatory genes are responsible for the formation of the ommatidia, which constitute the eye of the fruit fly Drosophila and of the mammalian eye. Furthermore, the transcription factor Pax6, like its Drosophila homolog eyeless, which is at the top of the regulatory cascade, can induce ectopic eye formation in the fly (Halder et al. 1995). The article by Heanue and collegues in this issue of Genes \& Development, demonstrates that the same combination of transcriptional regulators required for eye formation is redeployed elsewhere during vertebrate embryogenesis, in this case in the somite and its skeletal muscle derivatives.
\end{abstract}

\section{The network of genes implicated in Drosophila} eye formation

In Drosophila, the eyeless gene activates a cascade of genes (Halder et al. 1998), including eyes absent, dachshund, and sine oculis, with subsequent feedback to form a regulatory network (Fig. 1A), such that ectopic expression of dachshund (Shen \& Mardon 1997) or eyes absent (Chen et al. 1997; Pignoni et al. 1997), also leads to ectopic eye formation. sine oculis (Pignoni et al. 1997) and dachshund (Chen et al. 1997) are both capable of synergizing with eyes absent to promote this process and the proteins have been shown to form molecular complexes. While Sine oculis (So) and Eyeless (Ey) are homeodomain proteins and bind DNA, this is not the case for Eyes absent (Eya) and Dachshund (Dac) which probably act as transcriptional cofactors. In addition to these genes that are essential for eye formation, another gene, twin of

${ }^{1}$ Corresponding author.

E-MAIL margab@pasteur.fr; FAX 33140613452. eyeless, has been identified recently (Czerny et al. 1999). This gene appears to correspond to a duplication of eyeless that occurred during the radiation of insects. It acts upstream of eyeless but is not regulated by a feedback loop (Fig. 1A). This regulatory network does not necessarily function at other sites in the Drosophila embryo, in which these genes show different expression patterns and have different mutant phenotypes; for example, sine oculis expression elsewhere in the embryonic head is independent of eyeless and twin of eyeless (Halder et al. 1998).

\section{Vertebrate homologs of the Drosophila eye network}

Vertebrate homologs of these genes have now been identified (Fig. 1B), and as is often the case, they are present as multigene families with distinct if overlapping expression patterns. A subset is involved in eye development. Pax6 plays a similar role to that of eyeless (or twin of eyeless) and is a member of a large family of paired-domain proteins, many of which also have a homeodomain (for review, see Tremblay and Gruss 1994). Paired-domain proteins bind DNA, and different regions of the proteins may show activator or repressor functions in transcriptional assays. Pax genes are expressed, often in pairs, at different sites in the embryo. Mutations of many of them have now been analyzed in the mouse, in which they have been shown to play key roles in the development of tissues and organs. Outside their normal in vivo context, Pax genes also act as proto-oncogenes and a number of translocations involving human Pax genes may give rise to tumors (for review, see Tremblay and Gruss 1994). A striking feature of PAX genes is the number of spontaneous mutations that exist, illustrated by Pax6, which has been shown to be responsible for Small eye in the mouse and ANIRIDIA in humans. As in the Drosophila paradigm, ectopic expression of Pax6 can lead to eye formation (Jean et al. 1998; Chow et al. 1999).

The Six genes are homologs of sine oculis. To date, the number of Six gene family members is, coincidentally, six, and includes the related sequence Optx2 (Toy et al. 1998), or Six6 and Six3, which are closer homologs of the Drosophila sine oculis-related gene optix. Six genes are 
A
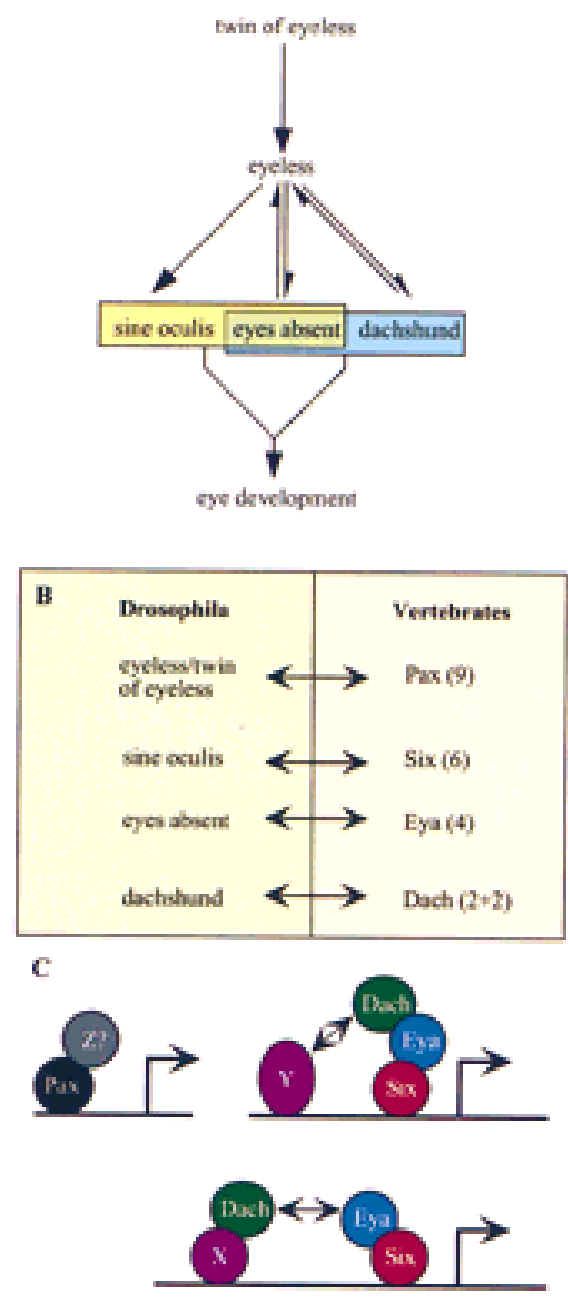

Figure 1. A network of regulatory genes involved in Drosophila eye formation conserved between insects and vertebrates. (A) The network of genes that regulates eye formation in Drosophila (see text for details). (B) Vertebrate homologs of these Drosophila genes. The number of related genes identified to date in vertebrates is indicated in parentheses. In vertebrates, two Dach genes have been described, as well as two Dachrelated genes, Ski and Sno $(+2) .(C)$ Putative models for transcriptional complexes formed by the Pax/Six/Eya/Dach proteins. Among these proteins, Six and Pax have DNA-binding domains. Biochemical interactions have been shown between Six/Eya and Eya/Dach through conserved domains. Dach may be part of an Eya/Six transcription complex, potentially interacting (arrows) with another adjacent transcription factor/complex $(Y)$, or it may interact with Eya as part of a complex with another DNA binding transcription factor $(X)$. Pax appears to bind to an independent site, possibly in association with cofactors $(Z)$. The angled arrows indicate transcriptional initiation sites.

also expressed at many different sites in the embryo, again often in pairs. Ectopic expression of Six3 in fish leads to changes in cell fate, with expression of lens and retinal markers (for review, see Jean et al. 1998; Loosli et al. 1999), whereas Optx2, in addition to affecting cell fate
(Toy et al. 1998), has also been implicated in the proliferative control of retinal cells (Zuber et al. 1999). Human SIX1, isolated in a screen for cell cycle-regulated genes from mammary carcinoma cells, abrogates the $G_{2}$ cell cycle checkpoint (Ford et al. 1998), pointing to a role for this gene family in growth control. Six proteins bind DNA and were identified independently of their homology to So, as transcription factors involved in the regulation of the ARE element of the ubiquitously expressed $\mathrm{Na}^{+} / \mathrm{K}^{+}$ATPase-1 subunit gene (Kawakami et al. 1996) and of the MEF3 element necessary for the expression in skeletal muscle of the Aldolase A (Spitz et al. 1997) and Myogenin (Spitz et al. 1998) genes. An indication of the possible consequences for skeletal muscle tissue of Six mutations is provided by the human disease Steinert's myotonic dystrophy, in which amplification of a trinucleotide repeat may perturb the regulation of Six5. This disease is accompanied by the down-regulation of genes that have MEF3 motifs in their regulatory elements (Spitz et al. 1997). As in the Drosophila eye, Six proteins cooperate with homologs of Eya to activate their target genes (Ohto et al. 1999) (Fig.1C).

Four Eya genes have been identified (Xu et al. 1997b; Borsani et al. 1999) and are expressed in partially overlapping patterns at different sites in the mouse embryo, including the lens and nasal placode where Eya1 and Eya2 transcripts overlap with and depend upon expression of Pax6 (Xu et al. 1997b). Haploinsufficiency for human EYA1 results in bronchio-oto-renal (BOR) syndrome (Abdelhak et al. 1997), and targeted mutation of the mouse Eya1 gene results in failure of ear and kidney development in homozygotes (Xu et al. 1999). Pax and Six genes are also expressed at these sites, and Six but not Pax gene expression is affected in the mutant. This observation is in keeping with the suggestion that $P a x$ genes (Pax6) may be more similar to Drosophila twin of eyeless, rather than eyeless (Fig. 1; Czerny et al. 1999). The Eya1 mutation does not affect eye development, presumably because of redundancy with Eya2. The loss of organs in this mutant has been attributed to a defect in inductive tissue interactions. Interestingly, the molecular interaction demonstrated for Six and Eya (Ohto et al. 1999) promotes nuclear translocation of Eya from the cytoplasm, reminiscent of what happens to $\beta$-catenin on reception of Wnt signalling. Their cooperative effect on transcription varies with different Eya/Six combinations, suggesting some specificity of interaction between isoforms. It is not yet clear by what mechanism transcription is activated. Six 4 has an intrinsic activation domain in the carboxyl terminus (Kawakami et al. 1996), while amino-terminal portions of Eya1-Eya3 show transactivation activity (Xu et al. 1997a). Six1 and Six4 alone can activate transcription through a multimerized MEF3 site from the Myogenin promoter, but this activation is weak (Spitz et al. 1998) and is only clearly evident in the presence of Eya binding to Six (Ohto et al. 1999).

The work on the Drosophila proteins showed that Eya also interacts with Dac (Fig. 1C; Chen et al. 1997). A mammalian homolog of the dachshund gene, named Dach (Hammond et al. 1998; Kozmik et al. 1999) or Dac 
(Caubit et al. 1999) has been isolated. It has a dynamic expression pattern during embryogenesis which includes the eye, limb, neural crest, and neocortex. Dach maps to the mouse Piebald locus and its absence may be responsible for the phenotype seen in some deletions of this region. The human $D A C$ gene maps to a syntenic region on human chromosome 13 also associated with neural crest deficiences, mental retardation, and occasional deficiences in limb and central nervous system (CNS) development (Caubit et al. 1999). Pax6 and Dach have overlapping domains of expression in the eye. However Dach expression is not affected in the mouse Small eye (Pax6) mutation (Hammond et al. 1998). Dach shows partial homology to the Ski proto-oncoprotein and related Sno proteins. Targeted disruption of the mouse Ski gene (Berk et al. 1997) demonstrates its importance for normal morphogenesis of the face and brain. The skeletal muscle mass is also reduced in the mutant. Over expression of Ski results in skeletal muscle hypertrophy (Sutrave et al. 1990), with fast fibers particularly implicated (Lana et al. 1996). Sno, like Ski, is expressed in many tissues, including neonatal and adult skeletal muscle (Pearson-White and Crittenden 1997). Although they have transforming activitiy, both Ski and Sno can convert muscle cells to myogenesis (Colmenares and Stavnezer 1989; Zheng et al. 1997), and Ski potentiates transcription from the Myogenin promoter in differentiating muscle cells (Ichikawa et al. 1997). Recently, it has been shown that Ski is a component of a histone deacetylase complex, modulating the effect on transcription of Mad and nuclear hormone receptors (Dahl et al. 1998; Nomura et al. 1999). In the myogenic context, Ski may inhibit transcriptional repression by such receptors. Another model, based on interaction between NF1 transcription factors and Ski (Tarapore et al. 1997), is suggested by studies on the muscle Aldolase A promoter, which is regulated by adjacent MEF3 and NF1 sites (Spitz et al. 1997). In this case, Eya2-Ski/Dach interaction would be facilited by their binding as cofactors to Six and NF1, respectively (see Fig. 1C). In such a model it is more evident to envisage Ski as a transcriptional activator of the Aldolase gene, which is expressed in fast muscle fibers, in which particular NF1 isoforms are present (Spitz et al. 1997). Part of the transforming activity of Ski, may be exercised via repression of Smad transcriptional activity and, hence, of transforming growth factor $\beta$ (TGF $\beta$ )-induced growth arrest (Luo et al. 1999).

\section{A novel Dach gene and expression of the regulatory network in somites}

In this issue, Heanue et al. (1999) report the isolation of a second vertebrate dachshund homolog, Dach2. This gene, isolated from chicken, can rescue the eye phenotype in dachshund mutant flies. Two protein domains are conserved between fly Dac and the vertebrate Dach, Dach2, Ski, and Sno proteins: a carboxy-terminal region which is involved in the formation of helical structures with other proteins, including Ski itself, which acts as a dimer; and an amino-terminal domain that is necessary for the transforming and myogenic properties of Ski and Sno proteins. In Drosophila dachshund this region is associated with transcriptional activation /Chen et al. 1997). Dach2, together with members of the Pax, Six, and Eya families are expressed in somites, in the domain that gives rise to skeletal muscle progenitors and subsequently in these cells. Indeed, it was the presence of $\mathrm{Pax}$, Six, and Eya transcripts, and the analogy with the situation in the Drosophila eye, which led Heanue et al. (1999) to look for expression of a dachshund homolog in the somite.

Somites (Fig. 2) form progressively during embryogenesis along the rostral-caudal axis by condensation of paraxial mesoderm on either side of the neural tube (for review, see Christ and Ordahl 1995; Tajbakhsh and Buckingham 1999). Initially the somite is a sphere of epithelial-type cells, which at this stage are multipotent. Their adoption of a cartilage, muscle or dermal cell fate depends on signals from surrounding tissues. As the somite matures, the dorsal dermomyotome retains an epithelial structure, whereas mesenchymal cells form the sclerotome ventrally. This compartment will give rise to the cartilage and bones of the vertebral column and at least part of the ribs. Skeletal muscle cells derive from the dermomyotome. Epaxial musculature (e.g., deep back muscles) derives from cells situated dorso-medially, adjacent to the neural tube, which migrate under the dermomyotome to form the differentiated muscle of the epaxial myotome (see Fig. 2). This process depends on signals from the notochord (e.g., Sonic hedgehog) and the neural tube (e.g., Wnts). Ventro-laterally, muscle progenitor cells in the dermomyotome will contribute to the hypaxial myotome that participates in the formation of ventral body muscles. The specification of hypaxial muscle cells depends on signals from the surface ecto-
Figure 2. Schema of somite maturation and early muscle formation. $(A)$ The epithelial somite; $(B)$ a more mature somite where cell fate has been specified.

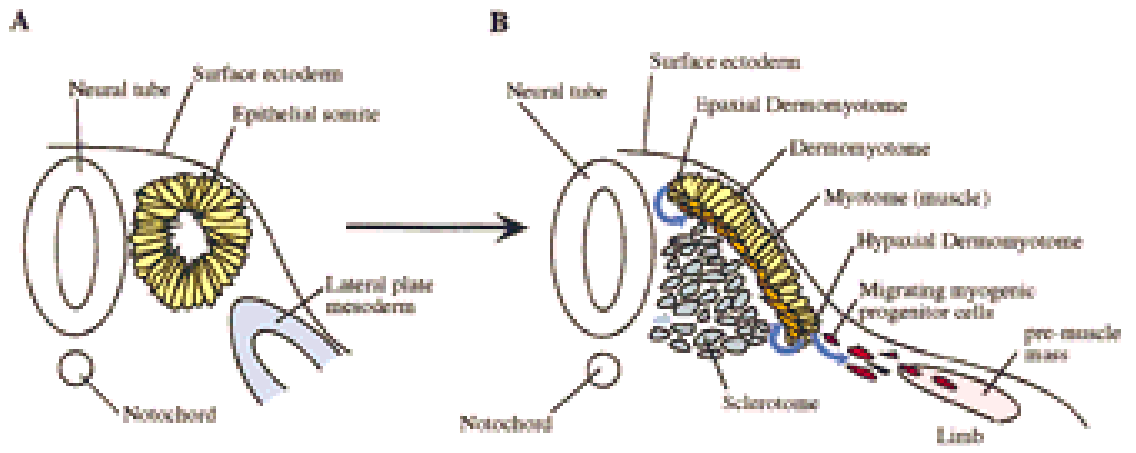


derm, also a source of Wnt signaling, and is retarded by lateral plate mesoderm, a source of bone morphogenetic proteins (BMP) and fibroblast growth factor (FGF) signals. Muscle progenitor cells also migrate out from this lateral part of the dermomyotome to form hypaxial muscle masses such as those of the limb (Fig. 2).

Pax3 (and Pax7) (for review, see Tajbakhsh and Buckingham 1999) is expressed in the dermomyotome, as well as in the presomitic paraxial mesoderm. As the somite matures Pax3 expression remains high in the hypaxial dermomyotome and in the myogenic progenitor cells that migrate from it. $\mathrm{Pax} 3$ transcripts are also detected later in differentiated muscle masses. In Splotch mice which carry mutations in the Pax3 gene, the hypaxial dermomyotome is foreshortened and migratory muscle progenitor cells do not leave it; limb muscles, for example, do not form. The Six1 gene in mouse /Oliver et al. 1995) and Six4 gene in chicken (Esteve and Bovolenta 1999) are also transcribed in presomitic mesoderm and in newly formed somites. As the somites mature, expression is restricted to the dermomyotome and later to the skeletal muscle mass of the myotome. It is also seen in developing limb buds, in which expression in connective tissue can be distinguished from that in muscle cells using Splotch mutant mice (Oliver et al. 1995). Both Six1 and Six 4 transcripts are also detected in adult skeletal muscle (see also Spitz et al. 1997). Expression of three of the four murine Eya genes has been documented in the epithelial somite, the dermomyotome, migrating muscle progenitor cells, and differentiated skeletal muscle (Xu et al. 1997b; Michima and Tomarev 1998; Borsani et al. 1999). At least in the case of Eya1 and Eya2, expression was also noted in presomitic mesoderm (Xu et al. 1997b). Dach transcripts were not detected in somites, although a recent report suggests that there may be low-level expression (Davis et al. 1999; Kozmik et al. 1999). Dach is expressed in a dynamic pattern in limb bud mesenchyme, but there is no evidence for expression in skeletal muscle (Hammond et al. 1998; Caubit et al. 1999).

Heanue et al. (1999) now show that Dach2 is expressed in the developing avian somite. As in the case of the other genes discussed, Dach2 expression is dynamic. Expression is not evident in presomitic mesoderm but is seen in the dorsal part of the somite as it forms. As the somite matures, Dach2 transcripts accumulate in the hypaxial part of the dermomyotome and are seen in migratory muscle progenitor cells and in the premuscle masses of the limb bud. Expression remains detectable in the epaxial dermomyotome immediately adjacent to the neural tube. Dach2 and Pax3 expression remains restricted to the dermomyotome, whereas Six1 and Eya2 transcripts become concentrated in the myotome. It remains to be seen whether Dach2 expression is detected later in differentiated skeletal muscle. It is possible that Ski/Sno, not Dach2, synergize with Six and Eya to activate and/or maintain transcription of skeletal muscle genes once muscle has formed. Dach2 is also expressed in lateral plate mesoderm and, like Pax3, in the dorsal neural tube.

The expression patterns of Dach2 and Pax3 are similar in the somite, and both have now been shown to depend on signals from the overlying surface ectoderm (Heanue et al. 1999; for review, see Tajbakhsh and Buckingham 1999|. It is not clear whether signals, such as the Wnts, which affect $P a x 3$, also activate and/or maintain Dach2 transcription independently or whether this is dependent on Pax3. Heanue et al. (1999) mention that in Splotch (Pax3 mutant) mice, Dach2 is expressed, although the Pax3 ortholog, Pax7, may be compensating for the loss of Pax3. However, in Pax6 mutants, Dach expression is also not affected (Hammond et al. 1998). Interestingly, Drosophila dachshund, which, in addition to the eye, is also expressed in the developing wing and limb of the fly, is regulated in the limb by a quantitative balance of the signaling molecules Wingless (Wnts) and Decapentaplegic (BMPs) (Lecuit and Cohen 1997), both present in the vicinity of the somite (for review, see Tajbakhsh and Buckingham 1999). In this context, potential transcriptional repression of BMP signaling by Dach2 as reported for Ski (Luo et al. 1999) may be important for muscle formation. Reciprocal regulation between Pax3 and Dach2 has been demonstrated in vitro in somite explant cultures. In these experiments, Pax3 and Dach2 transcripts, which are absent or present at a very low level in the explants, accumulate in the presence of Dach2 or Pax3, respectively. Pax3 expression also increases the level of Eya2 transcripts, but there is little effect on Six1, which is already transcribed at a high level in the explants (Heanue et al. 1999). This is similar to the dependency of Eya but not Six expression on Pax gene expression at other sites in the embryo (Xu et al. 1997b). Heanue et al. (1999) also examine the molecular interactions between these factors and show interactions between Eya2 and Dach2 or Eya2 and Six1. The latter interaction is not seen with Six3, which is the direct homolog of Drosophila Optix, rather than So (Toy et al. 1998). The interactions seen between these avian proteins are therefore similar to those described for Drosophila Eya/Dac (Chen et al. 1997) and Eya/So (Pignoni et al. 1997), as well as for murine Six and Eya proteins, where it was noted that Six3, unlike Six1, was ineffectual in inducing the nuclear translocation of Eya /Ohto et al. 1999).

\section{The genetic hierarchy which regulates myogenesis}

The formation of skeletal muscle in vertebrates depends on a family of genes that encode basic helix-loop-helix transcription factors. These myogenic regulatory factors transactivate many genes expressed in skeletal muscle and, furthermore, when overexpressed in nonmuscle cells, will convert them to muscle cells (Weintraub et al. 1991). Targeted mutations of the four genes of this family in the mouse (for review, see Tajbakhsh and Buckingham 1999) have demonstrated that Myogenin, which accumulates as myoblasts differentiate, is essential for skeletal muscle differentiation, whereas Myf5 and MyoD together play a role in the determination of myogenic progenitor cells; indeed, in the absence of both of these factors, somitic cells, which in response to exter- 
nal signals have activated one of these genes, migrate aberrantly and may assume cartilage or dermal cell fates (Tajbakhsh et al. 1996). More recently, it has been shown genetically that Pax3 and Myf5 act upstream of MyoD in determining skeletal muscle cell fate (Tajbakhsh et al. 1997); furthermore, ectopic expression of avian Pax3 will lead to $M y o D$ activation in certain cell types (Maroto et al. 1997).

Heanue et al. (1999) now investigate the potential of Dach2, Eya2, and Six1 for effecting myogenic conversion. They show that in somite explants in which-in the absence of surrounding tissues-no myogenesis takes place, expression of combinations of Six1 and Eya2 or Dach2 and Eya2 leads to activation of $M y o D$, Myogenin, and Myosin heavy chain genes. Again, this is reminiscent of the situation in the Drosophila eye. This finding therefore introduces these regulatory factors as key players, together with Pax3 and Myf5, in the genetic hierarchy that regulates myogenesis. Myf5 expression was not examined in the experiments described by Heanue et al. (1999); and indeed, in birds the relation between Myf5 and Pax3/MyoD has not been established clearly. Expression of either Dach2, Eya2, or Six1, led to a low level of $\operatorname{Pax} 3$ transcripts. Some $M y o D$ transcription was detectable but not activation of the muscle differentiation markers Myogenin and Myosin heavy chain. This probably reflects the low level of MyoD; Sixl alone, present already in quantity in the explants, is not capable of activating Myogenin transcription through the MEF3 site in the Myogenin promoter under these conditions. The simplest explanation of these observations is that Pax3, activated and/or maintained through a Dach/Eya/ Six feedback loop (Fig. 1A), mediates MyoD-driven myogenesis. However, there is no evidence that Pax3 directly activates $M y o D$; furthermore, expression of Myogenin clearly also depends directly on Six proteins (Spitz et al. 1998); it remains to be seen whether $M y o D$ regulatory sequences also contain MEF3 sites.

Other genes which are potential targets of Dach/Eya/ Six prior to the onset of muscle differentiation and that may depend on Pax3 expression include the c-met gene, encoding a tyrosine kinase receptor, and the homeobox gene $L b x 1$. These genes are also expressed in the dermomyotome and in migrating muscle progenitor cells. In both cases mutation of the genes (Bladt et al. 1995; Maina et al. 1996; Schäfer and Braun 1999l, results in a failure of cells to migrate into the limb and a consequent lack of limb muscles. Interestingly, this is not complete in the case of $L b \times 1$-null mice where some forelimb muscles are present (Schäfer and Braun 1999), and a hypomorphic mutation of c-met in which Grb2 signaling is uncoupled from the receptor also results in the loss or reduction of some skeletal muscles (Maina et al. 1995). Two other genes encoding homeodomain proteins, Msx1 (Houzelstein et al. 1999) and Mox2 (Mankoo et al. 1999), are also expressed in the dermomyotome and in migratory muscle cells. Again, mutation of Mox2 results in the loss of a subset of muscle masses in the limb (Mankoo et al. 1999). Mox2 expression does not depend on Pax3, and indeed both Pax3 and Myf5, but not MyoD are down- regulated in the limb buds of Mox2-deficient embryos (Mankoo et al. 1999). It will be important to see what happens to Dach/Eya/Six expression in the Mox2 mutant. In the absence of Pax3 this complex may be activating $M y o D$ in the limb.

\section{Functional considerations}

Formation of limb muscle, and other muscles derived from the hypaxial dermomyotome (see Fig. 2), depends on a number of critical steps: (1) survival and proliferation of myogenic progenitor cells in the dermomyotome epithelium; (2) delamination from this epithelium; (3) migration; (4) proliferation in the premuscle masses of the limb; and (5) activation of the myogenic program through Myf5 and/or MyoD.

Pax3 has been implicated in the first step (Borycki et al. 1999; see also Tajbakhsh and Buckingham 1999) and possibly in the proliferation of the premuscle masses. It is perhaps significant that Six proteins (Ford et al. 1998), as well as Ski/Sno, can affect cell proliferation. It has been proposed that Ski, which is expressed maximally in the skeletal muscle of limbs at embryonic day (E) 13.515.5 in the mouse plays a role in the amplification of the secondary myoblast population prior to the large increase in skeletal muscle mass which takes place at this time (see Berk et al. 1997). c-Met is necessary for delamination from the epithelium (Yang et al. 1996) and probably for migration (Bladt et al. 1995). Signaling through this receptor also probably affects the proliferation of at least part of the muscle precursor population in the limb (Maina et al. 1995). Lbxl plays a role in migration, perhaps through activation of another cell surface receptor involved in this process (Schäfer and Braun 1999). Mox2 (Mankoo et al. 1999) may also be necessary for the migration and for proliferation of a subpopulation of myogenic progenitor cells. Directly or indirectly it also affects Myf5 expression and hence activation of the myogenic program.

Activation of the myogenic program at the correct time and place is critical and repressing premature myogenesis may also require specific regulatory strategies. Pax3 and now Six and Eya are already expressed in the presomitic mesoderm, as well as in the dermomyotome and the cells that migrate from it. Dach2 is also expressed at the latter stages. Factors, or a combination thereof, which promote cell division (such as Pax and Six proteins, potentially) will tend to repress muscle differentiation, which is preceded by cell cycle withdrawal. Msxl represses myogenesis; in this case, direct binding of the homeoprotein to the MyoD enhancer has been shown (Woloshin et al. 1995). The formation of a complex between Msx1 and Pax3 has also been demonstrated in vitro (Bendall et al. 1999), although the in vivo significance in the somite in which Msx1 expression is low (Houzelstein et al. 1999) is not clear. Signaling from surrounding tissues is an important facet of this scenario (for review, see Cossu et al. 1996), leading to repression or activation of Myf5 and MyoD (for review, see Tajbakhsh and Buckingham 1999). Post-transcriptional 
modification of regulators such as Pax3, Dach/Eya/Six may be introduced as a result of such signaling. In this context, it is intriguing that Eya is subject to translocation from cytoplasm to nucleus (Ohto et al. 1999). At present, information about the expression of these genes is based almost entirely on detection of transcripts.

This discussion has focused on myogenic cells which derive from the hypaxial dermomyotome, where the necessity for Pax3 is evident. However, the role of Pax3 in epaxial myogenesis remains an enigma. Myf5 is activated initially in the epaxial dermomyotome and it is this myogenic factor that drives early myogenesis in the myotome. Later activation of $M y o D$, as a result of signals from an older neural tube and notochord, is delayed (Tajbakhsh et al. 1997) but occurs in the absence of Myf5 (for review, see Tajbakhsh and Buckingham 1999). In Splotch mice, epaxially derived muscles are present; however, in Splotch/Myf5 double mutant mice, no muscle forms in the trunk or appendages and MyoD does not rescue myogenesis at these sites (Tajbakhsh et al. 1997). Pax3 is required for the activation of $M y o D$ in the absence of Myf5, although Pax3 transcripts are downregulated in the epaxial dermomyotome by this stage in the mouse. Myf5 is necessary, prior to activation of the myogenic program, for the correct positioning of progenitor cells (Tajbakhsh et al. 1996), presumably via activation of a cell surface receptor. Pax3 plays this role in the hypaxial dermomyotome and it may also play such a role epaxially via a receptor such as c-Met, which is expressed in a few cells in the epaxial dermomyotome. Failure to activate $M y o D$ in the Splotch/Myf5 double mutant would then be due to incorrect positioning of progenitor cells.

The results reported by Heanue et al. (1999) now suggest another explanation. Pax3-dependent activation of Eya may be essential for $M y o D$ activation. Unlike Dach2, Eya and Six do not appear to be expressed at high levels in the epaxial dermomyotome of the chick embryo, but this remains to be investigated at the time of $M y o D$ activation in the mouse. Pax3, acting through Dach/Six/Eya, may therefore regulate transcription of $M y o D$ in both epaxial and hypaxial muscle cell derivatives, together with Myf5, which is probably situated in another regulatory network. Targeted mutations of the Dach, Six, and Eya genes expressed in the somite should clarify their position in this genetic hierarchy. Compensation by another member of the gene family may make this approach laborious. The manipulation of dominantnegative sequences is another possible approach. Exploring the function of these factors will provide interesting new insights into the regulation of myogenesis. Indeed, the redeployment of this Drosophila regulatory network not just for eye and muscle, but in many other developmental contexts in the vertebrate embryo, has widespread functional implications.

\section{Acknowledgments}

We thank Dr. P. Maire and members of the Buckingham Laboratory for comments and discussion.

\section{References}

Abdelhak, S., V. Kalatzis, R. Heilig, S. Compain, D. Samson, C. Vincent, D. Weil, C. Cruaud, I. Sahly, M. Leibovici et al. 1997. A human homolog of the Drosophila eyes absent gene underlies branchio-oto-renal (BOR) syndrome and identifies a novel gene family. Nat. Genet. 15: 157-164.

Bendall, A.J., J. Ding, G. Hu, M.M. Shen, and C. Abate-Shen. 1999. Msx1 antagonizes the myogenic activity of Pax3 in migrating limb muscle precursors. Development 126: 49654976.

Berk, M., S.Y. Desai, H.C. Heyman, and C. Colmenares. 1997. Mice lacking the ski proto-oncogene have defects in neurulation, craniofacial, patterning, and skeletal muscle development. Genes \& Dev. 11: 2029-2039.

Bladt, F., D. Riethmacher, S. Isenmann, A. Aguzzi, and C. Birchmeier. 1995. Essential role for the c-met receptor in the migration of myogenic precursor cells into the limb bud. $\mathrm{Na}$ ture 376: 768-771.

Borsani, G., A. DeGrandi, A. Ballabio, A. Bulfone, L. Bernard, S. Banfi, C. Gattuso, M. Mariani, M. Dixon, D. Donnai et al. 1999. EYA4, a novel vertebrate gene related to Drosophila eyes absent. Hum. Mol. Genet. 8: 11-23.

Borycki, A.G., J. Li, F. Jin, C.P. Emerson, and J.A. Epstein. 1999. Pax3 functions in cell survival and in pax7 regulation. Development 126: 1665-1674.

Caubit, X., R. Thangarajah, T. Theil, J. Wirth, H.G. Nothwang, U. Rüther, and S. Krauss. 1999. Mouse Dac, a novel nuclear factor with homology to Drosophila dachshund shows a dynamic expression in the neural crest, the eye, the neocortex, and the limb bud. Dev. Dyn. 214: 66-80.

Chen, R., M. Amoui, Z. Zhang, and G. Mardon. 1997. Dachshund and Eyes absent proteins form a complex and function synergistically to induce ectopic eye development in Drosophila. Cell 91: 893-903.

Chow, R.L., C.R. Altmann, R.A. Lang, and A. Hemmati-Brivanlon. 1999. Pax6 induces ectopic eyes in a vertebrate. Development 126: 4213-4222.

Christ, B. and C.P. Ordahl. 1995. Early stages of chick somite development. Anat. Embryol. 191: 381-396.

Colmenares, C. and E. Stavnezer. 1989. The ski oncogene induces muscle differentiation in quail embryo cells. Cell 59: 293-303.

Cossu, G., S. Tajbakhsh, and M. Buckingham. 1996. How is myogenesis initiated in the embryo? Trends Genet. 12: 218223.

Czerny, T., G. Halder, U. Kloter, A. Souabni, W.J. Gehring, and M. Busslinger. 1999. twin of eyeless, a second Pax-6 gene of Drosophila, acts upstream of eyeless in the control of eye development. Mol. Cell 3: 297-307.

Dahl, R., M. Kieslinger, H. Beug, and M.J. Hayman. 1998. Transformation of hematopoietic cells by the Ski oncoprotein involves repression of retinoic acid receptor signaling. Proc. Natl. Acad. Sci. 95: 11187-11192.

Davis, R.J., W. Shen, T.A. Heanue, and G. Mardon. 1999. Mouse Dach, a homologue of Drosophila dachshund, is expressed in the developing retina, brains and limbs. Dev. Genes Evol. 209: 526-536.

Esteve, P. and P. Bovolenta. 1999. cSix4, a member of the six gene family of transcription factors, is expressed during placode and somite development. Mech. Dev. 85: 161-165.

Ford, H.L., E.N. Kabingu, E.A. Bump, G.L. Mutter, and A.B. Pardee. 1998. Abrogation of the G2 cell cycle checkpoint associated with overexpression of HSIX1: A possible mechanism of breast carcinogenesis. Proc. Natl. Acad. Sci. 95: 12608-12613. 
Halder, G., P. Callaerts, and W.J. Gehring. 1995. Induction of ectopic eyes by targeted expression of the eyeless gene in Drosophila. Science 267: 1788-1792.

Halder, G., P. Callaerts, S. Flister, U. Walldorf, U. Kloter, and W.J. Gehring. 1998. Eyeless initiates the expression of both sine oculis and eyes absent during Drosophila compound eye development. Development 125: 2181-2191.

Hammond, K.L., I.M. Hanson, A.G. Brown, L.A. Lettice, and R.E. Hill. 1998. Mammalian and Drosophila dachshund genes are related to the Ski proto-oncogene and are expressed in eye and limb. Mech. Dev. 74: 121-131.

Heanue, T.A., R. Reshef, R.J. Davis, G. Mardon, G. Oliver, S. Tomarev, A.B. Lassar, and C.J. Tabin. 1999. Synergistic regulation of vertebrate muscle development by Dach2, Eya2, and Six1, homologs of genes required for Drosophila eye formation. Genes \& Dev. (this issue).

Houzelstein, D., G. Auda-Boucher, Y. Chéraud, T. Rouaud, I. Blanc, S. Tajbakhsh, M.E. Buckingham, J. Fontaine-Pérus, and B. Robert. 1999. The homeobox gene Msx1 is expressed in a subset of somites, and in muscle progenitor cells migrating into the forelimb. Development 126: 2689-2701.

Ichikawa, K., T. Nagase, S. Ishii, A. Asano, and N. Mimura. 1997. Trans-regulation of myogenin promoter/enhancer activity by c-ski during skeletal-muscle differentiation: The C-terminus of the c-Ski protein is essential for transcriptional regulatory activity in myotubes. Biochem. J. 328: 607613.

Jean, D., K. Ewan, and P. Gruss. 1998. Molecular regulators involved in vertebrate eye development. Mech. Dev. 76: 3 18.

Kawakami, K., H. Ohto, K. Ikeda, and R.G. Roeder. 1996. Structure, function and expression of a murine homeobox protein AREC3, a homologue of Drosophila sine oculis gene product, and implication in development. Nucleic Acids Res. 24: 303-310.

Kozmik, Z., P. Pfeffer, J. Kralova, J. Paces, V. Paces, A. Kalousova, and A. Cvekl. 1999. Molecular cloning and expression of the human and mouse homologues of the Drosophila dachshund gene. Dev. Genes Evol. 209: 537-545.

Lana, D.P., J.M. Leferovich, A.M. Kelly, and S.H. Hughes. 1996. Selective expression of a ski transgene affects IIb fast muscles and skeletal structure. Dev. Dyn. 205: 13-23.

Lecuit, T. and S.M. Cohen. 1997. Proximal-distal axis formation in the Drosophila leg. Nature 388: 139-145.

Loosli, F., S. Winkler, and J. Wittbrodt. 1999. Six3 overexpression initiates the formation of ectopic retina. Genes \& Dev. 13: 649-654.

Luo, K., S.L. Stroschein, W. Wang, D. Chen, E. Martens, S. Zhou, and Q. Zhou. 1999. The Ski oncoprotein interacts with the Smad proteins to repress TGF $\beta$ signaling. Genes \& Dev. 13: 2196-2206.

Maina, F., F. Casagranda, E. Audero, A. Simeone, P.M. Comoglio, R. Klein, and C. Ponzetto. 1996. Uncoupling of Grb2 from the Met receptor in vivo reveals complex roles in muscle development. Cell 87: 531-542.

Mankoo, B.S., N.S. Collins, P. Ashby, E. Grigorieva, L.H. Pevny, A. Candia, C.V. Wright, P.W. Rigby, and V. Pachnis. 1999. Mox2 is a component of the genetic hierarchy controlling limb muscle development. Nature 400: 69-73.

Maroto, M., R. Reshef, A.E. Munsterberg, S. Koester, M. Goulding, and A.B. Lassar. 1997. Ectopic Pax-3 activates MyoD and Myf-5 expression in embryonic mesoderm and neural tissue. Cell 89: 139-148.

Mishima, N. and S. Tomarev. 1998. Chicken Eyes absent 2 gene: Isolation and expression pattern during development.
Int. J. Dev. Biol. 42: 1109-1115.

Nomura, T., M.M. Khan, S.C. Kaul, H.D. Dong, R. Wadhwa, C. Colmenares, I. Kohno, and S. Ishii. 1999. Ski is a component of the histone deacetylase complex required for transcriptional repression by Mad and thyroid hormone receptor. Genes \& Dev. 13: 412-423.

Ohto, H., S. Kamada, K. Tago, S.I. Tominaga, H. Ozaki, S. Sato, and K. Kawakami. 1999. Cooperation of Six and Eya in activation of their target genes through nuclear translocation of Eya. Mol. Cell. Biol. 19: 6815-6824.

Oliver, G., R. Wehr, N.A. Jenkins, N.G. Copeland, B.N.R. Cheyette, V. Harstenstein, S.L. Zipursky, and P. Gruss. 1995. Homeobox genes and connective tissue patterning. Development 121: 693-705.

Pearson-White, S. and R. Crittenden. 1997. Proto-oncogene Sno expression, alternative isoforms and immediate early serum response. Nucleic Acids Res. 25: 2930-2937.

Pignoni, F., B. Hu, K.H. Zavitz, J. Xiao, P.A. Garrity, and S.L. Zipursky. 1997. The eye-specification proteins So and Eya form a complex and regulate multiple steps in Drosophila eye development. Cell 91: 881-891.

Schäfer, K. and T. Braun. 1999. Early specification of limb muscle precursor cells by the homeobox gene Lbx1h. Nat. Genet. 23: 213-216.

Shen, W. and G. Mardon. 1997. Ectopic eye development in Drosophila induced by directed dachshund expression. Development 124: 45-52.

Spitz, F., M. Salminen, J. Demignon, A. Kahn, D. Daegelen, and P. Maire. 1997. A combination of MEF3 and NFI proteins activates transcription in a subset of fast-twitch muscles. Mol. Cell. Biol. 17: 656-666.

Spitz, F., J. Demignon, A. Porteu, A. Kahn, J.P. Concordet, D. Daegelen, and P. Maire. 1998. Expression of myogenin during embryogenesis is controlled by Six/sine oculis homeoproteins through a conserved MEF3 binding site. Proc. Nat1. Acad. Sci. 95: 14220-14225.

Sutrave, P., A.M. Kelly, and S.H. Hughes. 1990. ski can cause selective growth of skeletal muscle in transgenic mice. Genes \& Dev. 4: 1462-1472.

Tajbakhsh, S. and M. Buckingham. 1999. The birth of muscle progenitor cells in the mouse: Spatiotemporal consideration. Curr. Top. Dev. Biol. Somitogenesis 48: 225-268.

Tajbakhsh, S., D. Rocancourt, and M. Buckingham. 1996. Muscle progenitor cells failing to respond to positional cues adopt non- myogenic fates in myf-5 null mice. Nature 384: 266-270.

Tajbakhsh, S., D. Rocancourt, G. Cossu, and M. Buckingham. 1997. Redefining the genetic hierarchies controlling skeletal myogenesis: Pax-3 and Myf-5 act upstream of MyoD. Cell 89: $127-138$

Tarapore, P., C. Richmond, G. Zheng, S.B. Cohen, B. Kelder, J. Kopchick, U. Kruse, A.E. Sippel, C. Colmenares, and E. Stavnezer. 1997. DNA binding and transcriptional activation by the Ski oncoprotein mediated by interaction with NFI. Nucleic Acids Res. 25: 3895-3903.

Toy, J., J.M. Yang, G.S. Leppert, and O.H. Sundin. 1998. The optx2 homeobox gene is expressed in early precursors of the eye and activates retina-specific genes. Proc. Natl. Acad. Sci. 95: 10643-10648.

Tremblay, P. and P. Gruss. 1994. Pax: Genes for mice and men. Pharmacol. Ther. 61: 205-226.

Weintraub, H., R. Davis, S. Tapscott, M. Thayer, M. Krause, R. Benezra, K. Blackwell, D. Turner, R. Rupp, S. Hollenberg et al. 1991. The myoD gene family: Nodalpoint during specification of the muscle cell lineage. Science 251: 761-766. 
Woloshin, P., K. Song, C. Degnin, A.M. Killary, D.J. Goldhamer, D. Sassoon, and M.J. Thayer. 1995. MSX1 inhibits myoD expression in fibroblast $\times 10 \mathrm{~T} 1 / 2$ cell hybrids. Cell 82: 611620.

Xu, P.X., J. Cheng, J.A. Epstein, and R.L. Maas. 1997a. Mouse Eya genes are expressed during limb tendon development and encode a transcriptional activation function. Proc. Natl. Acad. Sci. 94: 11974-11979.

Xu, P.X., I. Woo, H. Her, D.R. Beier, and R.L. Maas. 1997 b. Mouse Eya homologues of the Drosophila eyes absent gene require Pax6 for expression in lens and nasal placode. Development 124: 219-231.

Xu, P.X., J. Adams, H. Peters, M.C. Brown, S. Heaney, and R. Maas. 1999. Eya1-deficient mice lack ears and kidneys and show abnormal apoptosis of organ primordia. Nat. Genet. 23: 113-117.

Yang, X.M., K. Vogan, P. Gros, and M. Park. 1996. Expression of the met receptor tyrosine kinase in muscle progenitor cells in somites and limbs is absent in Splotch mice. Development 122: 2163-2171.

Zheng, G., J. Teumer, C. Colmenares, C. Richmond, and E. Stavnezer. 1997. Identification of a core functional and structural domain of the $\mathrm{v}$-Ski oncoprotein responsible for both transformation and myogenesis. Oncogene 15: 459-471.

Zuber, M.E., M. Perron, A. Philpott, A. Bang, and W.A. Harris 1999. Giant eyes in Xenopus laevis by overexpression of XOptx2. Cell 98: 341-352. 


\section{Erratum}

Genes \& Development 13: 3171-3332, 1999.

The page numbers on the cover spine do not correspond to the actual pagination of this issue, which is indicated above. 


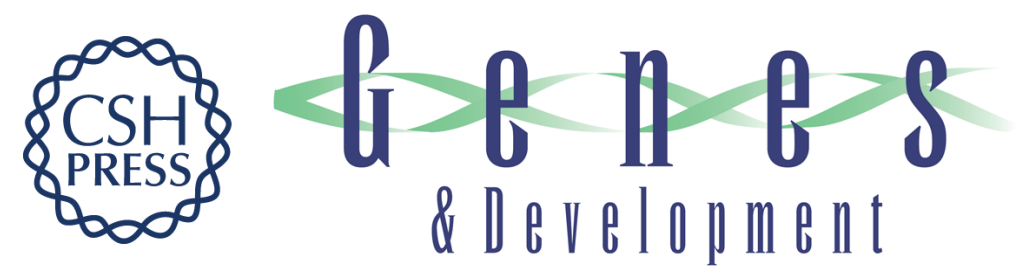

\section{From insect eye to vertebrate muscle: redeployment of a regulatory network}

Frédéric Relaix and Margaret Buckingham

Genes Dev. 1999, 13:

Related Content Genes Dev. January, 2000 14: 255

References This article cites 55 articles, 23 of which can be accessed free at: http://genesdev.cshlp.org/content/13/24/3171.full.html\#ref-list-1

Articles cited in:

http://genesdev.cshlp.org/content/13/24/3171.full.html\#related-urls

License

Email Alerting Receive free email alerts when new articles cite this article - sign up in the box at the top Service right corner of the article or click here.

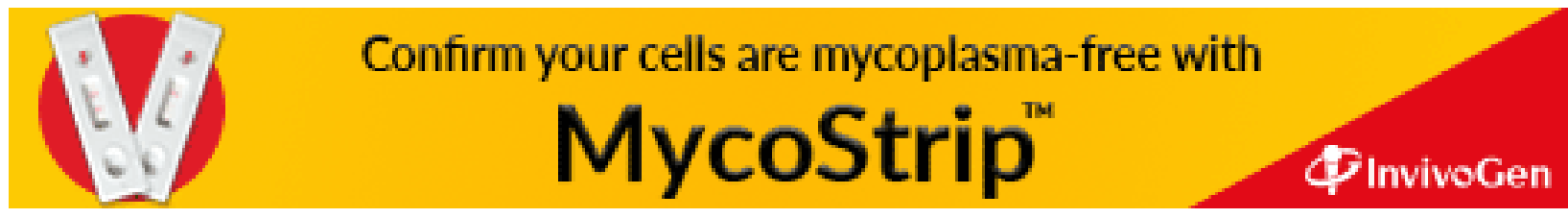

